\title{
THEORETICAL ANALYSIS OF MODEL SEABED BEHAVIOR UNDER WATER WAVE EXCITATION
}

\author{
ANDRZEJ SAWICKI, JACEK MIERCZYŃSKI, MARCIN SMYCZYŃSKI \\ IBW PAN, ul. Kościerska 7, 80-328 Gdańsk, Poland, \\ e-mail: a.sawicki@ibwpan.gda.pl,j.mierczynski@ibwpan.gda.pl,m.smyczynski@ibwpan.gda.pl
}

\begin{abstract}
Theoretical analysis of the behavior of a model seabed subjected to water wave excitation is presented. The experiments were performed in the wave flume at the Danish Technological University in Lyngby. Such experiments are unique in engineering sciences and therefore provide unique empirical data for testing various models of the seabed. A controversial explanation of the experiments is presented in the literature. The goal of this research was to study pore pressure changes caused by water waves and the subsequent liquefaction of the seabed. The authors of the present contribution offer their own theoretical explanation of the wave flume experiments and discuss errors found in the literature cited. The analysis is based on the classical soil mechanics, including the Biot type approach.
\end{abstract}

Key words: seabed, liquefaction, wave-flume experiments, saturated soil

\section{INTRODUCTION}

The problem of seabed stability is one of the key issues in marine engineering, as it includes the safety of various structures, sediment transport, etc. One of the most important mechanisms influencing the seabed stability is the phenomenon of liquefaction, which may be induced by such excitations as earthquakes or water waves. It was shown that these two kinds of excitation lead to different mechanisms of pore pressure generation and possible liquefaction, see Sawicki [4]. In the same paper, some fundamental errors in the modeling of wave-induced liquefaction by Sumer and Fredsoe [11] are discussed. This shows that the problem of seabed liquefaction is still not well understood, and further research, both theoretical and experimental, is necessary.

It should be mentioned that there is a lack of sufficient experimental data dealing with the pore pressure changes and possible liquefaction of the seabed caused by water waves, see Kirca et al. [1], Massel et al. [2], [3]. However, the experimental results obtained and their interpretation raise fundamental questions about the mechanism of seabed liquefaction. This paper is devoted to the theoretical analysis of experimental results obtained by Kirca et al. [1], as their research seems to be controversial.

\section{WAVE-FLUME EXPERIMENTS}

The experiments of Kirca et al. [1] were conducted in a wave flume $(26.5 \mathrm{~m}$ long and $0.6 \mathrm{~m}$ wide) specially prepared for liquefaction tests. The water depth was kept constant $(h=30 \mathrm{~cm})$. The soil was placed in a rectangular pit: $0.4 \mathrm{~m}$ deep, $0.6 \mathrm{~m}$ wide and $0.78 \mathrm{~m}$ long. According to Kirca et al., the pit was filled with silt, but it seems that it was rather a silty sand. The following characteristics of the soil used in the experiments are given by the authors:

- specific gravity $\gamma_{s} / \gamma_{w}=2.67$, where $\gamma_{s}$ - specific weight of grains, $\gamma_{w}$ - specific weight of water;

- specific gravity of the soil was defined as $\gamma_{t} / \gamma_{w}=$ 1.83;

- the coefficient of lateral pressure at rest was estimated from Jaky's equation $K_{0}=1-\sin \phi=$ 0.42 , where $\phi=35.2^{\circ}$ is the angle of internal friction;

- the coefficient of permeability was $k=1.5 \times 10^{-5} \mathrm{~m} / \mathrm{s}$, which is typical of silty sands rather than of silts;

- the minimum and maximum void ratios were $e_{\min }=0.57$ and $e_{\max }=1.2$;

- porosity was $n=0.51$ and the relative density was $D_{r}=0.28$

- Poisson's ratio was $v=0.29$.

Important parameters, such as the shear modulus and other mechanical parameters of the soil, were not 
quoted. Other details of the experiments are presented in the original publication by Kirca et al. [1]. For our purposes, it is important to know the wave parameters, which are the following:

- wave length $L=156 \mathrm{~cm}$,

- wave period $T=1.09 \mathrm{~s}$,

- wave height $H$ varied from 5.9 to $12 \mathrm{~cm}$.

Pore pressures were measured at eight points of the model seabed. Figure 1 shows a scheme of the experimental set-up. Pore pressure gauges were installed in the pit at different depths and locations, cf. Kirca et al. [1].

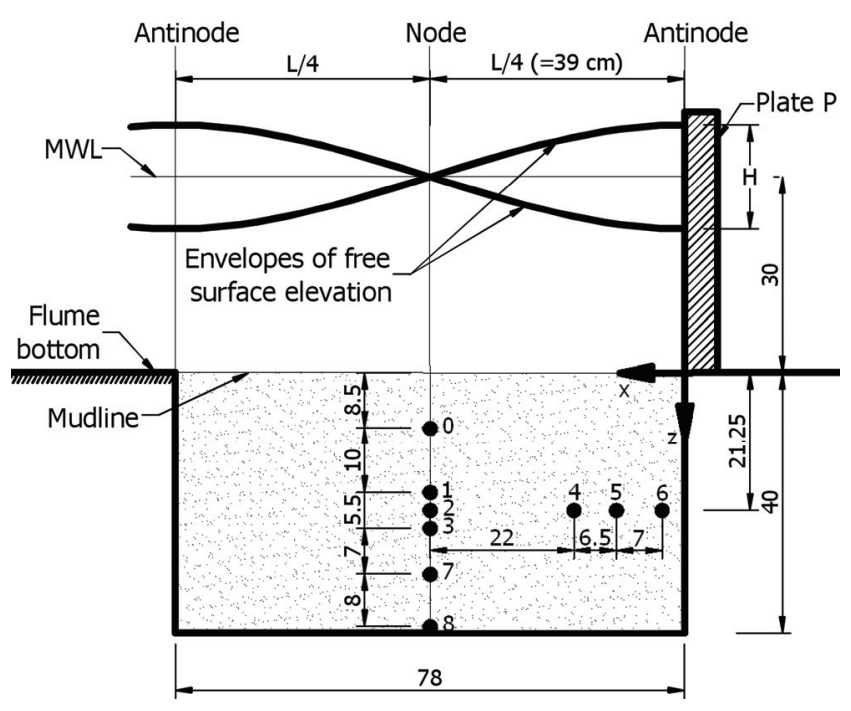

Fig. 1. Experimental set-up

\section{COMMENTS AND QUESTIONS}

The results obtained by Kirca et al. [1] lead to various questions dealing with the experiments themselves, as well as with their interpretation and conclusions. The most important can be summarized as follows:

a. The curve shown in Fig. 2, as well as some other curves corresponding to different gauges, exceeds the level of $p_{0}^{\prime} / \gamma_{w}$, which corresponds to liquefaction, as the mean effective stress is equal to zero, for $u=p_{0}^{\prime}$, where $p_{0}^{\prime}$ denotes the initial mean effective stress and $u$ denotes the excess pore pressure. Note that we have slightly changed the notation in comparison with that applied by Kirca et al. [1]. For example, we use the symbol $\gamma_{w}$ instead of $\gamma, u$ instead of $p$, etc. The reason is that the notation of Kirca et al. [1] is unusual in soil mechanics, and it is better to use commonly known symbols.

b. An interesting question is: how is it possible that they recorded excess pore pressures larger than $p_{0}^{\prime}$ ? Given the current knowledge of soil mechanics, it is impossible, particularly as these records show pore pressure accumulation. One possible explanation is that the experiments are erroneous, but for the sake of clarity, let us assume that the experimental results are correct.

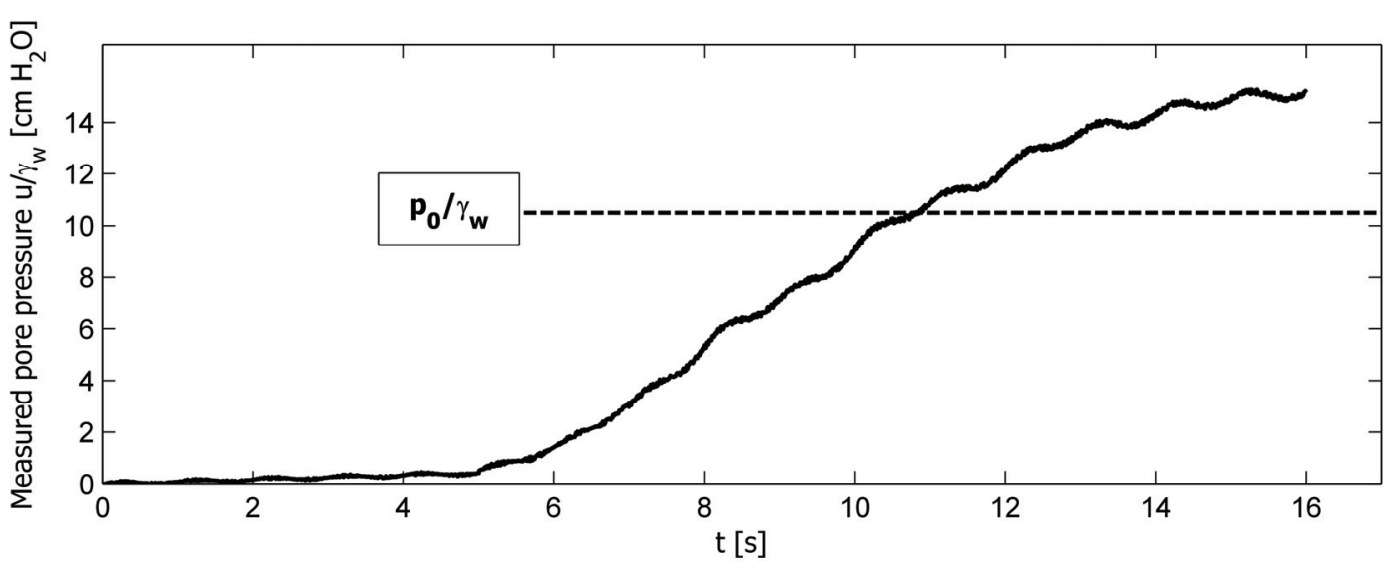

Fig. 2. Pore pressure build-up caused by water waves

Figure 2 shows a typical record, drawn after Fig. 4a of Kirca et al. [1], which illustrates pore pressure build-up caused by water waves. Note that there are small oscillations imposed on the mean trend, corresponding to the cyclic character of excitement.
Another possible explanation is therefore that some unknown mechanism induced such unusual changes in excess pore pressures. Perhaps the wave-induced pressures at the mudline are so strong that they cause effects which are beyond the scope of soil mechanics research. They may 
be associated with the intrinsic changes in pore pressure and the related mechanisms described in Sawicki [5], Sawicki and Mierczyński [6], Sawicki et al. [7]. These problems will be discussed in detail in subsequent sections.

c. An unusual sketch of shear stress variation in the seabed is shown in Fig. 3 of Kirca et al. [1]. They show only variations of a single component $\tau$ of the stress tensor. Moreover, if shear stresses are taken into account, the formalism of tensor algebra should be satisfied, which is ignored by Kirca et al. [1]. This means that the cyclic changes in the vertical and horizontal stresses are disregarded. Note that it is the invariants of the deviatoric stress that are responsible for soil behavior, certainly not a single component of the stress tensor, as suggested by Kirca et al. [1].

d. "Conclusions" and many other parts of the paper by Kirca et al. [1] contain some unacceptable statements and omissions. For example, the authors do not provide the value of shear modulus $G$ of the silty sand used in their experiments. Moreover, they state that "... the change in the soil behavior (stress-strain relation, friction angle) with depth is not significant" (page 500, of Kirca et al. [1]), which is wrong, as the shear modulus is one of the key parameters governing soil behavior. Their suggestion that "...transport is caused by a diffusion mechanism with a diffusion coefficient equal to the coefficient of consolidation..." is not supported by any rational arguments.

\section{THEORETICAL ANALYSIS USING THE BIOT-TYPE APPROACH}

The Biot-type approach has become a kind of standard in marine engineering since the publication of the well-known paper of Yamamoto et al. [12]. This approach is based on the assumptions of an elastic soil skeleton and isotropy. Such a simple model may perhaps be useful for some preliminary analyses of the behavior of granular soils, but it certainly does not lead to realistic physical results. There are two main shortcomings of the approach presented by Yamamoto et al. [12]. The main is the assumption of an elastic soil skeleton, which leads to physically inadmissible effective stress states. Additionally, the Biot-type approach does not take into account the dependence of the shear modulus on the mean effective stress, which is one of the key issues in the mechanics of liquefaction. These shortcomings have been corrected by Sawicki and Staroszczyk [8], who supplement the Biot-type equations with plasticity relations and take into account a physically realistic shear modulus. The results of applying the Biot-type approach for the interpretation of experimental data presented in Kirca et al. [1] will be shown in this section.

\section{Initial data}

The basic data are listed in Section 2. As already mentioned, the key parameter of the shear modulus $G$ was ignored by Kirca et al. Therefore, we can only speculate about its value for the soil used in experiments. It should be mentioned that the shear modulus generally depends on the mean effective stress $p_{0}^{\prime}$, the shear stress amplitude (the second invariant of the deviatoric stress) and the initial void ratio $e_{0}$. The shear modulus is usually determined from triaxial tests, which are performed at stresses of the order of $100 \mathrm{kPa}$ $=10^{5} \mathrm{~N} / \mathrm{m}^{2}$. Note that in small-scale laboratory experiments, stresses are much smaller, and it is very difficult to determine the value of the shear modulus in such cases. Sawicki et al. [9], [10] studied this problem in the context of shaking table experiments.

\section{Boundary condition at the mudline}

Water waves, shown in Fig. 1, exert some pressure at the mudline, which can be determined by hydrodynamic methods. Its amplitude has the following form

$$
u_{b}=\frac{\gamma_{w} H}{2 \cosh (\lambda h)},
$$

where $\lambda=2 \pi / L$ is the wave number.

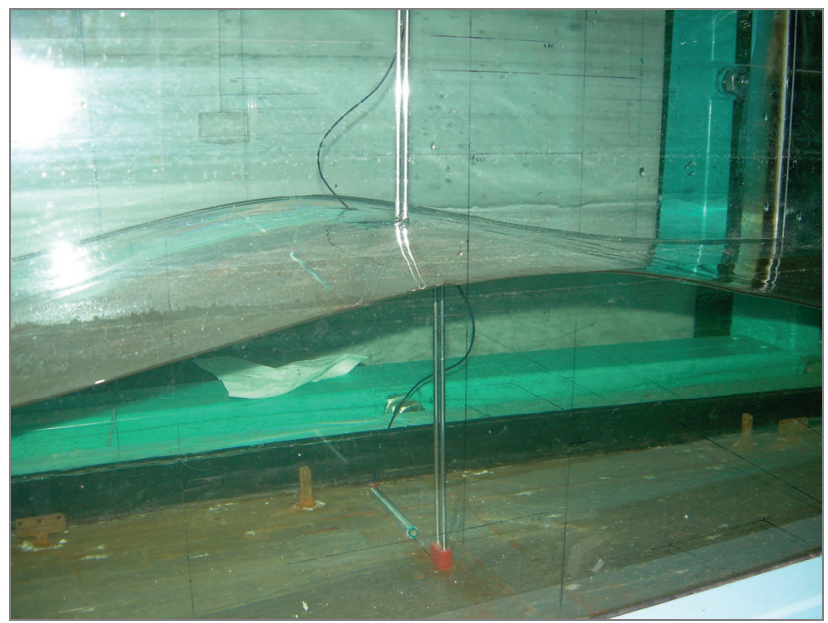

Fig. 3. Experimental set-up for measuring wave-induced pressures at the mudline 


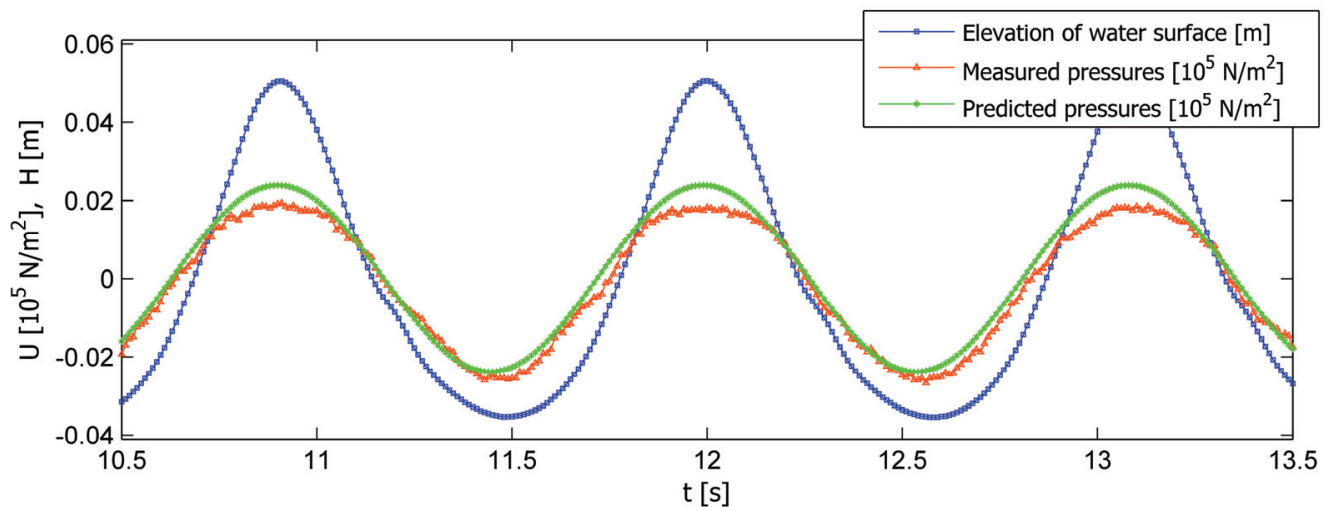

Fig. 4. Measured and predicted wave-induced pressures at the mudline

We have checked this condition experimentally in a wave flume. Figure 3 shows the experimental set-up. There were two gauges installed at a single crosssection of the channel. One gauge measured the elevation of the water surface, and the other indicated pressures at the mudline.

Figure 4 shows a typical record for the following data: $H=0.087 \mathrm{~m}, h=0.3 \mathrm{~m}, T=1.09 \mathrm{~s}$. The upper curve shows the measured wave-induced pressures at the mudline. The lower curve corresponds to the pressure predicted from equation (1). It follows from Fig. 4 that for small values of the ratio $H / h$, the theoretical formula (1) roughly coincides with the experimental results.

\section{Statically inadmissible effective stresses and liquefaction}

Consider, for the sake of convenience, the solution for a completely saturated seabed presented by Yamamoto et al. [12]. The corresponding equation for the wave-induced excess pore pressure is the following

$$
u=u_{b} \exp (-\lambda z) \exp [i(\lambda x+\omega t)]
$$

Its real part is the following

$$
u=u_{b} \exp (-\lambda z) \cos (\omega t) .
$$

The initial mean effective stress (static) is the following

$$
p_{0}^{\prime}=\frac{1}{3}\left(1+2 K_{0}\right) \gamma^{\prime} z
$$

where

$$
\gamma^{\prime}=\gamma_{\text {sat }}-\gamma_{w}
$$

is the buoyant unit weight of the soil.

The mean effective stress in the seabed is a difference between the initial (geostatic) effective stress and the wave-induced pore pressure, i.e.,

$$
p^{\prime}=p_{0}^{\prime}-u \text {. }
$$

It should be non-negative $\left(p_{0} \geq 0\right)$. Let us apply this simple method to the analysis of experimental data presented by Kirca et al. [1]. The following data are assumed: $\lambda=4.028 \mathrm{~m}^{-1} ; \gamma^{\prime}=0.08 \times 10^{5} \mathrm{~N} / \mathrm{m}^{2}$; $p_{0}^{\prime}=0.049 \times 10^{5} \mathrm{~N} / \mathrm{m}^{2} ; u_{b}=0.00323 \times 10^{5} \mathrm{~N} / \mathrm{m}^{2}$, which correspond to experimental conditions.

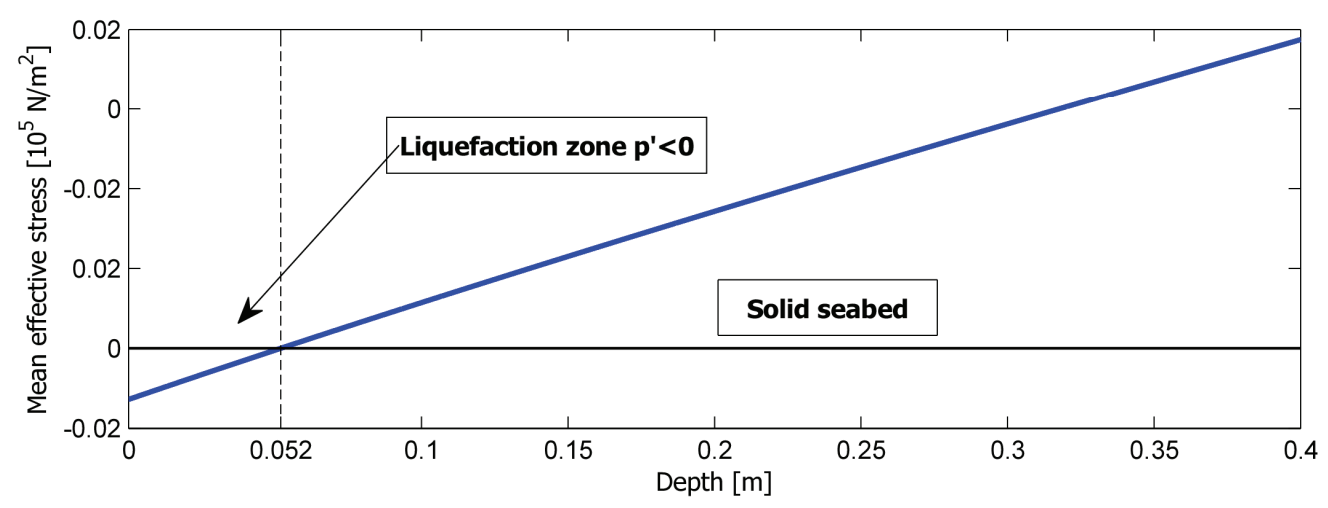

Fig. 5. Distribution of the mean effective stress for the experiments of Kirca et al. [1], according to the Biot-type approach 
The mean effective stress for extreme conditions ( $x=0$ and $\cos (\omega t)=-1)$ is the following

$$
p^{\prime}=0.05 z-0.0032 \exp (-4.028 z) \text {. }
$$

Figure 5 shows the distribution of $p^{\prime}$ with depth. It is seen that, according to the Biot-type approach, in the upper part of the subsoil, down to approximately $0.05 \mathrm{~m}$, the mean effective stress is negative, which is physically inadmissible. Below this level, the seabed is solid, as $p_{0}^{\prime} \geq 0$. This situation means that some regrouping of effective stresses (increase in $K_{0}$ ) should take place near the mudline, see Sawicki [4]. Note that the initial mean effective stress is not exceeded as much as indicated in Fig. 2.

\section{CONCLUSIONS}

The results presented in this communication can be summarized as follows:

a. The wave flume experiments described by Kirca et al. [1] cannot be properly described by the Biottype approach, whose predictions differ from the results of these experiments.

b. The discussion presented in Section 3 should be taken into account in further analysis of waveinduced pore pressures.

c. The pressure exerted by waves at the mudline can be approximated by the well-known hydrodynamic formula, which is supported by experimental data.

d. The surprising result shown in Fig. 2 should be examined carefully by other methods of applied mechanics.

\section{ACKNOWLEDGEMENT}

Presented research was supported by the EU program MERMAID, which is kindly acknowledged.

\section{REFERENCES}

[1] Kirca V.S.O., Sumer B.M., Fredsoe J., Residual liquefaction of seabed under standing waves, Journal of Waterway, Port, Coastal \& Ocean Engineering, ASCE, 2013, 139(6), 489-501, DOI: 10.1061/(ASCE)WW.19435460.0000208 .

[2] Massel S.R., Przyborska A., Przyborski M., Attenuation of wave-induced groundwater pressure in shallow water. Part 1, Oceanologia, 2004, 46(3), 383-404.

[3] Massel S.R., PrZyborska A., PrZyborski M., Attenuation of wave-induced groundwater pressure in shallow water. Part 2, Oceanologia, 2005, 47(3), 291-323.

[4] SAWICKI A., Mechanics of seabed liquefaction and resolidification, Archives of Mechanics, 2014, 66(5), 307-328.

[5] SAWICKi A., The Puzzle of Soil Liquefaction, IBW Publishing House, Gdańsk 2014.

[6] SAwicki A., MierCZyŃski J., Some effects of intrinsic cyclic loading in saturated sand, Journal of Theoretical and Applied Mechanics, 2015, 53(2), 285-293, DOI: 10.15632/ jtam-pl.53.2.285.

[7] Sawicki A., MierczyŃsKi J., ŚWidzińsKi W., Apparent creep of saturated sand caused by intrinsic cyclic loading, J. Geotech. \& Geoenvironmental ASCE, 2013, 140(2), DOI: 10.1061/(ASCE)GT.1943-5606.0001025.

[8] SAWICKi A., STARoszczyK R., Wave-induced stresses and pore pressures near a mudline, Oceanologia, 2008, 50(4), 539-555.

[9] SAWICKI A., ŚWIDZIŃSKI W., KULCZYKOwSKI M., Shaking table dynamics of a dry sand layer, Proc. 2nd Int. Conf. on Performance Based Design in Earthquake Geotechnical Engineering, Int. Soc. Soil Mech. Geotech. Eng., Taormina, Italy, 2012, 661-668.

[10] SAWICKI A., ŚwidzińSKi W., MiERcZYŃSKi J., Modut ścinania gruntu sypkiego przy matych naprężeniach (Shear modulus of granular soils at low stresses), Czasopismo Techniczne, Politechnika Krakowska, 3-Ś/2012, 2012, 109(27), 91-102.

[11] Sumer B.M., Fredsoe J., (2002): The Mechanics of Scour in the Marine Environment, World Scientific, New Jersey-Singapore-London-Hong Kong, 2002, DOI: 10.1142/ 97898127776070010.

[12] Yamamoto T., Koning H.L., Sellmeijer H., Van Hijum E., On the response of a poro-elastic bed to water waves, Journal of Fluid Mechanics, 1978, 87(1), 193-205. DOI: $10.1017 / \mathrm{S} 0022112078003006$. 